\title{
Observational study of aggressive behaviour and coercion on an Indian acute ward
}

Danivas, Vijay; Lepping, Peter; Punitharani, Shivanna; Gowrishree, Handithavalli; Ashwini, Kundapur; Raveesh, Benivahalli; Palmstierna, Tom

\section{Asian Journal of Psychiatry}

DOI:

10.1016/j.ajp.2016.06.004

Published: 01/08/2016

Peer reviewed version

Cyswllt i'r cyhoeddiad / Link to publication

Dyfyniad o'r fersiwn a gyhoeddwyd / Citation for published version (APA):

Danivas, V., Lepping, P., Punitharani, S., Gowrishree, H., Ashwini, K., Raveesh, B., \&

Palmstierna, T. (2016). Öbservational study of aggressive behaviour and coercion on an Indian acute ward. Asian Journal of Psychiatry, 22(August), 150-156.

https://doi.org/10.1016/j.ajp.2016.06.004

\footnotetext{
Hawliau Cyffredinol / General rights

Copyright and moral rights for the publications made accessible in the public portal are retained by the authors and/or other copyright owners and it is a condition of accessing publications that users recognise and abide by the legal requirements associated with these rights.

- Users may download and print one copy of any publication from the public portal for the purpose of private study or research.

- You may not further distribute the material or use it for any profit-making activity or commercial gain

- You may freely distribute the URL identifying the publication in the public portal ?
}

Take down policy

If you believe that this document breaches copyright please contact us providing details, and we will remove access to the work immediately and investigate your claim. 
Title:

Observational study of aggressive behaviour and coercion on an Indian acute ward

Highlights:

1. Aggression in Indian psychiatry wards appear to be higher compared to European settings

2. Presence of relatives on wards shifts the target of violence from staff to relatives

3. Relatives are a significant resource in the management of incidents

4. Aggression towards staff is more likely to lead to coercive measures 
Title:

Observational study of aggressive behaviour and coercion on an Indian acute ward

\author{
Authors: \\ Vijay Danivas, MD (1) \\ Peter Lepping, MD, MSc, MRPsych, Professor $(1,2,3)$ \\ Shivanna Punitharani (1) \\ Handithavalli Gowrishree (1) \\ Kundapur Ashwini (1) \\ Bevinahalli Nanjegowda Raveesh, MD, Director, Professor $(1,4)$ \\ Tom Palmstierna, MD, PhD, Professor $(5,6)$ (corresponding author) \\ (1) Department of Psychiatry, Mysore Medical College and Research Institute, Mysore, India \\ (2) Betsi Cadwaladr University Health Board, Wrexham, United Kingdom \\ (3) Centre for Mental Health and Society, Bangor University, Wrexham, United Kingdom \\ (4) Dharwad Institute of Mental Health and Neurosciences, Dharwad, India \\ (5) Department of Clinical Neuroscience, Centre for Psychiatric Research, Karolinska \\ Institutet, Stockholm Sweden \\ (6) Norwegian University of Science and Technology, Department of Neuroscience, St. Olav's \\ University Hospital, Forensic Research Unit, Brøset, Trondheim, Norway
}

Corresponding author:

Tom Palmstierna

Phone: +91-9886274497

e-mail:

vijaydanivas@gmail.com

Postal adress:

Department of Psychiatry

Mysore Medical College and Research Institute,

Irwin Road,

Mysore - 570001 


\section{Abstract}

Objective: We evaluated prevalence of aggressive behaviour and coercive measures on an acute Indian psychiatric ward where relatives are always present at the ward. Method: Noninteracting, independent observers (specifically trained mental health clinicians) on an Indian acute, 20-bedded psychiatric ward gave structured reports on all violent episodes and coercive measures during a 30-day period. They used the Staff Observation Aggression Scale -Revised, Indian (SOAS-RI). The severity of the SOAS-RI reports were independently analysed by one of the authors. Results: 229 violent incidents were recorded, involving 63\% of admitted patients. $27 \%$ of all admitted patients were subjected to intravenous injections. Relatives provoked $35 \%$ of the incidents and were the target in $56 \%$ of the incidents. Patients ' own relatives were involved in managing the aggression in $35 \%$ of the incidents. Relatives of other patients were involved in $14 \%$ of the incidents. The likelihood of a patient to be physically restrained and that a relative would be participating in the coercive measures was increased when medical staff was targeted. Conclusion: Relatives are commonly triggers and victims of aggressions on the inverstigated acute Indian psychiatric wards. Doctors and nurses are less likely to be victims but aggression towards them leads more commonly to coercive measures.

\section{Highlights:}

1. Aggression in Indian psychiatry wards appear to be higher compared to European settings

2. Presence of relatives on wards shifts the target of violence from staff to relatives

3. Relatives are a significant resource in the management of incidents

4. Aggression towards staff is more likely to lead to coercive measures

\section{Key words:}

Relatives, Violence, Coercion, inpatients, 


\section{Title: Observational study of aggressive behaviour and coercion on an Indian}

acute ward

\section{Background:}

Violence and aggression at the workplace happens across all medical specialties (Sabine Hahn, 2008) and psychiatric inpatients wards are no exception. Significant interest has been shown in understanding patient violence as it has been shown to have a negative impact on staff motivation, job satisfaction and the quality of care delivered to patient. More recently, intervention studies have shown effective ways to reduce violence and coercive measures in psychiatric settings (Abderhalden et al., 2008; van de Sande et al., 2011) paving the way for significant improvements.

Cornaggia et al found a prevalence of $3 \%$ to $15 \%$ of psychiatric inpatients displaying assaultive behaviour throughout a variety of high income countries (Cornaggia et al., 2011). Beghi and colleagues report a prevalence of the use of restraint of between $3.8 \%$ and $20 \%$

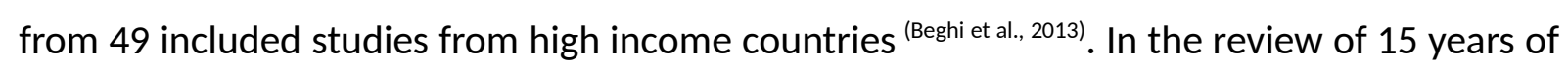
research using the aggression reporting tool SOAS-R, Nijman et al conducted a meta-analysis of all studies that used SOAS and found a mean of 9.3 aggressive incidents per patient per year. The range varied between 0.4 to 33.2 incidents per patient per year. This study established SOAS-R as the standard instrument for reporting aggression, especially in Europe, and comparable across populations. (Nijman et al., 2005) The Annual National Audit of Violence conducted by the UK Royal College of Psychiatrists in 2007 studied multiple details around aggression in 215 NHS hospitals across England and Wales, and remains the single largest data set on violence towards mental health staff. It reported that about $46 \%$ of mental health care workers were physically assaulted in the previous year and a significant 72\% had felt threatened or unsafe in their career(RCPsych, 2007).

Data on aggressive inpatient behaviour on psychiatric wards from middle and low income countries are scarce. A recent study from India, looking into patient and visitor violence 
towards staff $(n=249)$ found that $57 \%$ of staff in medical wards and $16 \%$ of staff in psychiatric wards were victims of aggression in the previous 4 weeks. The study used an adapted selfreport questionnaire, the so called Survey of Violence experienced by Staff (SOVES) (Raveesh et al., 2015). One other study from Bangalore, India, reported patient violence experienced by $87 \%$ of psychiatric nurses (Balamurugan et al., 2012).

Studies assessing violence in patients with psychiatric disorders are based on recall of aggressive incidents by staff using surveys or on incident reporting forms. Recall of the incidents by the staff is limited by recall bias. The Staff Observation Aggression Scale Revised (SOAS-R) is a validated instrument for reporting aggressive behaviour from patients in psychiatric institutions, and has become the standard instrument for aggression research in Europe over the past 30 years (Nijman and Rector, 1999; Palmstierna and Wistedt, 1987). Using a standard reporting scale like the SOAS-R allows for systematic reporting and analysis. Reporting, however relies on staff being present everywhere on the ward at the time of an incident and having the motivation to report it (Lion et al., 1981). Therefore, underreporting remains variable and limits a comprehensive reporting of incidents, especially when the severity of the violent incidents is low, which is why many previous studies using the SOAS-R use a cut-off that leaves the less severe incidents out of the analyses (Abderhalden et al., 2008; Palmstierna and Olsson, 2007). Ideally, data should be collected by independent observers present on the wards at all times, but such research has so far been impossible to conduct for logistical and economic reasons(Brizer et al., 1988).

The striking difference between psychiatric care in high income and middle and low income countries is the constant presence in the latter of a non-professional caregiver with every patient, mostly a close relative. They are practically involved in nursing care, but it is unclear to what degree this supports or hinders recovery. This classically happens in Indian governmental health care settings who often cater for patients from lower socio-economic backgrounds. This setting brings the most important caregiver to the hospital ward, and allows observation of the dynamics between patients, relatives and professional staff. To the best of our knowledge, there has been no study from India reporting prevalence data on aggression and coercion in acute psychiatric wards. 
The aims of the current study were to

i. Examine the prevalence of inpatient aggression and subsequent coercive measures in a setting with non-professional care givers (relatives) in attendance of the patient.

ii. Analyse factors influencing the choice of immediate coercive measures as a reaction to aggression from patients.

iii. Explore the role of non-professional care givers in being instigators and targets of violence and their participation in coercive measures

\section{Materials and Methods:}

\subsection{Study design:}

We conducted an observational study of all levels of aggression and coercion on two acute psychiatric inpatient wards in Mysore, Karnataka, India. To guarantee continuous and independent observation, two psychologists and one social worker (PR, AKS \& GH) observed the wards during the working hours (from 8 a.m. to 10 p.m.) without interfering in any way. An intern doctor on duty continued the observation during the night. The observation period was 30 days in March and April 2015. Patient data including the socio-demographic variables and ICD-10 diagnoses, as well as ward data including admission and discharge dates. These data were obtained from the patient case files and ward inpatient records. The study was approved by the Mysore Medical College and Research Institute's (MMCRI) institutional ethics committee.

\subsection{Setting:}

The study was conducted in the psychiatric inpatient unit of Mysore Medical College and Research Institute (MMCRI), a tertiary care referral hospital located in southern India. This is a state run hospital serving a catchment area of 1,500,000 with 135 primary health centres. The department houses 20 beds, 10 each for male and female patients. The two wards for men and women are separated and comprised of dormitory accommodation. The wards are large rooms shared by 10 patients with nursing staff overlooking the wards. Though the wards are considered open wards, the main entrance leading on to these wards is gated. There is round the clock security available at the entrance. At least 2 nursing staff and one junior doctor working in shifts will be in the ward at any point of time apart from night shifts when nursing staff is reduced to one nurse for both wards. Psychologists and psychiatrists are present in the ward for at least 8 hours a day and are available on-call out of hours. As a 
hospital policy one non-professional carer, preferably, and mostly a close relative has to be with the patient at all times. The vast majority of patients treated in the study setting come from lower socio-economic backgrounds, are severely ill at the time of admission, and are admitted against their will.

\subsection{Standard Medications used:}

As a standard operating procedure in the ward, whenever a patient needs parenteral medications, intravenous haloperidol $5 \mathrm{mg}$ with lorazepam $4 \mathrm{mg}$ are given. Haloperidol $5 \mathrm{mg}$ with promethazine $25 \mathrm{mg}$ are given when intramuscularly injections are required.

\subsection{Instrument:}

The SOAS-R is a reporting form for aggressive incidents (Henk L I Nijman et al., 1999). It allows staff to report such incidents and includes information about provocation, means used, targets, consequences and immediate measures to stop the aggression. The observer subjectively judges whether the incident was provoked and by whom. The SOAS-R entails a scoring system to assess the severity of the incident. It is only used for patients' aggressive behaviour. Examples of incidents classed as severe (score>8) include: any physical attack resulting in a visible injury, physical pain or the victim feeling threatened, physical attack with a dangerous object resulting in the patient being restrained.

We adapted the SOAS-R report form to cater for the presence of non-professional care givers (SOAS-RI, see appendix 1). These adaptations include the presence of security staff, relatives and other care givers. It allows for the categorisation of the aggressor other than the patient. Furthermore, a column for reporting people involved in measures to stop the aggressive incident was added. In contrast to all other studies of inpatient aggressive behaviour using the SOAS-R, the reporting of aggressive incidents in this study does not rely on the nursing staff on the ward, but utilises independent and non-intervening observers. This observational technique, see e.g. Brizer et al (Brizer et al., 1988) was tried out in the early 1980-ies, but was found to be too cumbersome and expensive. It was therefore abandoned in high income countries when techniques relying on staff observations were introduced (Henk L I Nijman et al., 1999; Kay et al., 1988; Palmstierna and Wistedt, 1987). However, relying on the nursing staff's reports inherently introduces the strong possibility of observer bias, which is seldom addressed in previous studies. By using reports from independent and non-intervening 
observers, it is much more likely to achieve more reliable reports on violent interactions in psychiatric wards.

\subsection{Statistics:}

This study is an observational study from a psychiatric ward within a treatment and nursing context that is quite different from most other studies on violent behaviours. Most results are therefore purely descriptive in order to make comparisons with other studies.

Analyses of predictors of different kinds of coercive measures applied are performed with logistic regressions. Four separate logistic regression models were analysed. Each reported incidents as the observational unit for analyses. In the four separate models, the outcomes "Hands-on" coercive measure (i.e. physical intervention); intravenous coercion (i.e. the use of intravenous injections as a response to a violent act); patient's relative engaged in coercive measures and doctor or nurse involved in measures to stop aggression were used as dichotomous dependent variables. In the unadjusted models, the variables from the SOAS$\mathrm{R} /$ Indian report form were used. Independent variables from the columns "provocation" and "target of aggression" were used as dichotomous variables. As independent variables from "means used by the aggressor" and "resulting injury", we used the predefined scores of severity, as defined by the original SOAS-R (Henk L I Nijman et al., 1999). A score of more than 8 in the SOAS-RI was considered a severe aggressive incident in line with previous studies using the SOAS-R ${ }^{(3,13)}$. In the adjusted models, the significant variables from the unadjusted models were used in a stepwise forward model in order to determine the strongest predictors in an incident predicting the different outcomes of the four models. We performed a Kruskal Wallis Test to examine whether there are statistically significant differences between main diagnostic categories with regard to frequency of incidents and coercive measures. In these analyses, we used IBM SPSS Statistics, Version 21, release 21.0.0.0.

\subsection{Results:}

\subsection{Demographics}


On the first day of the study, 16 patients were present in the ward. There were 47 patients admitted to the ward during the study period of 30 days. One patient was admitted twice during the 30 days study period. We had 387 occupied bed days, i.e. a mean occupancy of 12.9 beds with an occupancy rate of $64.5 \%$. There were 19 women and 44 men, mean age 35.8 (SD: 11.2 range 17-69). The main diagnostic category (according to ICD-10) was psychosis with $44 \%$, followed by alcohol dependence with $33 \%$, mania with $19 \%$ and others with $4 \%$. The mean observation time for mania patients was 6.42 days, for psychosis patients 6.25 days, and for alcohol dependency patients 4.71 .

During the study period a total of 241 aggressive incidents were reported in the ward. In 229 of those the patient was the aggressor. In six incidents a relative was reported as the aggressor, in five it was security staff and in one a ward assistant. In eight of these incidents with an aggressor other than the patient, the target was a patient, in three a relative and in one staff was targeted. Five of the incidents with aggressors other than patients could be classified as severe. Table 1 summarises the characteristics of the aggressive incidents with patients as aggressors.

Of the 229 incidents from patients, 128 were severe (by scoring > 8). This amounts to an average of 7.6 aggressive and 4.3 severely aggressive patient incidents per day. The frequency of physical attacks by patients was 3.4 incidents per day. This results in an average of 0.59 aggressive patient incidents per occupied bed day, and 0.33 for severe incidents. The number of incidents per 100 admissions per month is 487.2 . The number of patients affected by physical restraint per 100 admissions per month was 51.1 . The number of aggressive incidents per 100 occupied bed days per month was 59.17. 6.20 patients were affected by restraint per 100 occupied bed days per month. Table 2 gives the summary of the results for all parameters from the SOAS-RI report form.

$40(63 \%)$ patients were responsible for the 229 incidents on the wards. 24 (38\%) patients were subjected to any coercive measure; out of these, 17 (27\%) patients were subjected to intravenous injections. The median number of coercive measures per patient was 1 . One patient was subjected to 15 intravenous injections, thus skewing the overall numbers. It is worth noting that none of the incidents were associated with the use of dangerous or 
harmful objects, a significant minority of the relatives of other patients were affected by aggressive incidents ( 3 incidents). Only three (1.3\%) of the 229 incidents led to visible injuries, none required medical treatment.

\subsection{Relatives in Aggressive Incidents}

Patients' relatives were involved in a significant number of incidents. Patient's relatives provoked $35 \%$ of the incidents and $2 \%$ of the incidents were provoked by another patient's relative. In $56 \%$ of the incidents the patient's relative was the target of the aggression, in $1 \%$ another patient's relative was targeted. When people were involved in stopping the aggression, the patient's relative was involved in 35\% of cases, other patient's relatives in $14 \%$. Relatives were involved in both cases of mechanical restraint and in $81 \%$ of manual restraints. In $54 \%$ of incidents of intravenous injections, relatives were involved in helping the medical staff administer the injection.

We conducted logistic regressions; see descriptions above and table 3 for the significant unadjusted results. The following aspects were statistically significant in the four adjusted models, table 4:

1. If the target of the aggression was a doctor or nurse, the likelihood of any chemical or physical restraint was increased (OR: 3.10 for any restraint; OR: 4.41 for intravenous injection)

2. If the target of the aggression was a doctor or nurse, the likelihood of a relative being involved in stopping the aggression increased (OR: 3.35).

3. An increase in incident severity led to an increased likelihood of any chemical or physical restraint being used (OR: 1.21 for any restraint; OR: 1.20 for intravenous injection), but not to an increased likelihood of relatives being involved.

\subsection{Diagnostic categories:}

We created 3 main diagnostic categories for the Kruskal Wallis test: Psychosis $(n=28)$, Mania $(n=12)$ and Alcohol dependence $(n=21)$. The remaining 2 patients could not be included into any of the above categories and were therefore not included in the analyses. We found no significant difference between diagnostic categories and the frequency of incidence per day, 
the frequency of physical attacks on a person per day and the frequency of severe incidents per day (SOAS-RI score $>8$ ).

We did not find any statistically significant differences between diagnostic categories and the frequency of occasions when patients' relatives were involved in coercive measures per day. For mania, we did find a trend towards a higher frequency of intravenous injections per day (Chi square $=5.361 ; \mathrm{df}=2 ; \mathrm{p}=0.069$ ) and the number of "hands on" coercive measures (Chi square $=5.961 ; \mathrm{df}=2 ; \mathrm{p}=0.051)$.

\subsection{Discussion:}

The current study looked into the frequency of aggression, the role of relatives and coercive measures in the inpatient ward of a general hospital psychiatric unit in India. The total number of incidents appears high compared to admission wards in high income countries (Nijman et al., 2005). It is unclear whether this is a real difference or whether underreporting in comparable studies from high income countries is the reason for the difference. Studies from high income countries are dependent on staff motivation to report. They therefore often focus on more severe incidents, whereas our data includes all levels of incident severity with a preponderance of low level aggression and hardly any reported injuries. This indicates that under-reporting is unlikely in our data.

In Indian government settings, admission criteria focus on the need for additional care that cannot be provided in the patient's home by the family. There is therefore a selection bias towards more severely disturbed and unmanageable behaviour as compared to high income country admission wards. Our methodology is likely to cover a higher number of occurring incidents because of our use of independent persistent observation, thus eliminating underreporting bias. The low number of visible injuries supports the high coverage of real and less severe incidents.

\subsection{Aggression towards hospital staff:}

Aggression towards doctors and nurses are seen in only $15 \%$ of the incidents. This is much lower than in high income countries and probably due to the fact there are far fewer nurses on Indian wards compared to staffing levels in high income countries. The low figure may also be explained by the fact that the patients' relatives spend more direct time with the patient than staff (RCPsych, 2007). We have shown in a study from North Wales that direct contact time with patients is directly correlated with increased exposure to aggression and 
violence (Lepping et al., 2013). Alas, the most striking observation in our study is about the patients' relatives. Relatives provoked about $35 \%$ of the incidents and were commonly involved in controlling aggression by either talking to the patient or participating in coercion. More severe aggressive incidents and attacks on nursing and medical staff are more likely to lead to coercive measure than incidents targeting relatives. This opens up questions about how to best minimise risk to relatives whilst they are caring for the patients on the wards. Relatives were more likely to get involved when such incidents occurred, thus effectively becoming members of the nursing team. Furthermore, our data shows that most interventions are reactive rather than proactive. Recent evidence-based measures to predict and reduce aggression and restrictive coercive practices on psychiatric wards could be adapted to reduce risk to relatives and staff as well as the reactive use of coercion (Abderhalden et al., 2008; van de Sande et al., 2011). These observations may become very relevant to psychiatric practice in highincome countries too, as more relative involvement is considered in dementia care. Questions about how to protect, but also how to potentially train relatives in order to have safe and meaningful involvement in the patient's care remain, and strategies need to be developed to facilitate good outcome.

\subsection{Relatives of the patients in the ward:}

The other key outcome of the present study is the report of the role of the patient's relative in aggression as well as its management in acute psychiatric in-patient settings. Some possible explanations for our results are:

1. The obligation of caring for the patients partially shifts unknowingly and unintentionally from the nursing staff to the relatives. This shifts the target of aggression from the medical staff towards the relatives, who thus act as buffers.

2. The same change of obligation of caring increases the participation of relatives in coercive measures.

3. Relatives' presence on the ward in acutely disturbed psychiatric patients may in itself increase aggressive incidents.

The presence of relatives on the ward therefore presents challenges and opportunities for the nursing and caring of the patient. Whilst on the one hand, the risk to relatives of being victims of violence has to be addressed, the presence of non-professional care givers on the other hand opens up the opportunity for continuous psycho-education and treatment once the patient has been discharged, taking into account the risk of violent 
altercations after discharge. This potentially allows for intense treatment to continue at home, led by family members, supervised and guided by staff. This may reduce risk of violence in the long term. Further studies are needed to examine the dynamics of the presence of relatives in relation to violence and coercion using a qualitative approach. Psycho-educational interventions could be investigated. This can include options hitherto not considered in high income countries.

\subsection{Strengths and Limitations:}

The current study has significant methodological strengths. This is the first ever study reporting of non-professional care giver involvement in hospital care. It is one of the first studies to incorporate an independent and consistent observer rating, giving a consistency in reporting. We believe, though this research method is resource intensive, it is unbiased as the observers are very rarely part of the violence or coercion, thus ensuring neutrality and objectivity. It also prevents biased underreporting which is a basic methodological problem with the wide spread use of the SOAS-R, staff reporting system. Also, we believe that the psychiatric ward in Mysore is typical of general hospital psychiatric units in middle and low income countries in Asia. We therefore believe that the findings are generalisable to settings in the Indian subcontinent and beyond.

\subsection{Conclusions:}

\section{Acknowledgements:}

The authors acknowledge the inputs by Dr Manoj Mutalik, Dr Manjushree, Dr Melvin D'Souza, Dr Mohan Kumar Notagar, Dr Merin Babu, Dr Nagaraj Moger, Dr Mohammed Shihab as non-interacting observers in the ward.

\section{References:}

Abderhalden, C., Needham, I., Dassen, T., Halfens, R., Haug, H.J., Fischer, J.E., 2008. Structured risk assessment and violence in acute psychiatric wards: randomised controlled trial. The British journal of psychiatry : the journal of mental science 193, 4450 . 
Balamurugan, G., Jose, T.T., Nandakumar, P., 2012. Patients' violence towards nurses: a questionnaire survey. International Journal of Nursing 1, 7.

Beghi, M., Peroni, F., Gabola, P., Rossetti, A., Cornaggia, C.M., 2013. Prevalence and risk factors for the use of restraint in psychiatry: a systematic review. Rivista di psichiatria 48, 10-22.

Brizer, D.A., Crowner, M.L., Convit, A., Volavka, J., 1988. Videotape recording of inpatient assaults: a pilot study. The American journal of psychiatry 145, 751-752.

Cornaggia, C.M., Beghi, M., Pavone, F., Barale, F., 2011. Aggression in psychiatry wards: a systematic review. Psychiatry research 189, 10-20.

Henk L I Nijman, Muris, P., Merckelbach, H.L.G.J., Palmstierna, T., Wistedt, B.r., Vos, A.M., Rixtel, A.v., Allertz, W., 1999. The Staff Observation Aggression Scale- Revised (SOAS-R). Agressive Behavior 25, 13.

Kay, S.R., Wolkenfeld, F., Murrill, L.M., 1988. Profiles of aggression among psychiatric patients. I. Nature and prevalence. The Journal of nervous and mental disease 176, 539546.

Lepping, P., Lanka, S.V., Turner, J., Stanaway, S.E., Krishna, M., 2013. Percentage prevalence of patient and visitor violence against staff in high-risk UK medical wards. Clinical medicine 13, 543-546.

Lion, J.R., Synder, W., Merrill, G.L., 1981. Underreporting of assaults on staff in a state hospital. Hospital \& community psychiatry 32 , 497-498.

Nijman, H.L., Palmstierna, T., Almvik, R., Stolker, J.J., 2005. Fifteen years of research with the Staff Observation Aggression Scale: a review. Acta psychiatrica Scandinavica 111, $12-$ 21.

Nijman, H.L., Rector, G., 1999. Crowding and aggression on inpatient psychiatric wards. Psychiatric services 50, 830-831.

Palmstierna, T., Olsson, D., 2007. Violence from young women involuntarily admitted for severe drug abuse. Acta psychiatrica Scandinavica 115, 66-72.

Palmstierna, T., Wistedt, B., 1987. Staff observation aggression scale, SOAS: presentation and evaluation. Acta psychiatrica Scandinavica 76, 657-663. 
Raveesh, B.N., Lepping, P., Lanka, S.V., Turner, J., Krishna, M., 2015. Patient and visitor violence towards staff on medical and psychiatric wards in India. Asian journal of psychiatry $13,52-55$.

RCPsych, 2007. Healthcare Commission National Audit of Violence 2006-7. Final Report Working age adult services. Royal College of Psychiatrists, London.

Sabine Hahn, A.Z., Ian Needham, Gerjo Kok, Theo Dassen, Ruud J.G. Halfens, 2008. Patient and visitor violence in general hospitals: A systematic review of the literature. Aggression and Violent Behavior 13, 11.

van de Sande, R., Nijman, H.L., Noorthoorn, E.O., Wierdsma, A.I., Hellendoorn, E., van der Staak, C., Mulder, C.L., 2011. Aggression and seclusion on acute psychiatric wards: effect of short-term risk assessment. The British journal of psychiatry : the journal of mental science 199, 473-478.

\begin{tabular}{|l|l|l|}
\hline Table 1 & Nggression by patients (N=229) & \% of incidents \\
\hline Total number of reported incidents with patient as aggressor & 229 & $100,0 \%$ \\
\hline Number of severe incidents (scoring >8 on the SOAS-RI) & 128 & $55,9 \%$ \\
\hline Number of incidents resulting in "hands-on" coercive measures & 77 & $33,6 \%$ \\
\hline Number of incidents with physical attacks towards a person & 101 & $44,1 \%$ \\
\hline $\begin{array}{l}* \text { "'hand-on" means that the patient was restrained by physical interventions including physical restraint, } \\
\text { mechanical restraint, intramuscular or intravenous injections }\end{array}$ \\
\hline
\end{tabular}





\begin{tabular}{|c|c|c|c|c|c|c|c|c|c|c|c|c|c|c|c|c|c|}
\hline \multicolumn{3}{|c|}{ Provocation } & \multicolumn{3}{|c|}{ Means used by the patient } & \multicolumn{3}{|c|}{ Target of Aggression } & \multicolumn{3}{|c|}{ Consequences of aggression } & \multicolumn{3}{|c|}{ Measures to stop aggression } & \multicolumn{3}{|c|}{ People involved in measures } \\
\hline & $\mathbf{N}$ & $\%$ & & $\mathbf{N}$ & $\%$ & & $\mathbf{N}$ & $\%$ & & $\mathbf{N}$ & $\%$ & & $\mathbf{N}$ & $\%$ & & $\mathbf{N}$ & $\%$ \\
\hline $\begin{array}{l}\text { No understandable } \\
\text { provocation }\end{array}$ & 51 & 22,3 & $\begin{array}{l}\text { Verbal } \\
\text { aggression }\end{array}$ & 200 & 87,3 & None & 27 & 11,8 & None & 99 & 43,2 & None & 43 & 18,8 & No one & 43 & 18,8 \\
\hline $\begin{array}{l}\text { Provoked by other } \\
\text { patient }\end{array}$ & 19 & 8,3 & $\begin{array}{l}\text { Ordinary objects } \\
\text { on ward (e.g. } \\
\text { glassware, chair) } \\
\end{array}$ & 14 & 6,1 & $\begin{array}{l}\text { Objects } \\
\text { targeted }\end{array}$ & 7 & 3,1 & $\begin{array}{l}\text { Damage to } \\
\text { property }\end{array}$ & 4 & 1,7 & $\begin{array}{l}\text { Patient only talked } \\
\text { to or gently brought } \\
\text { away }\end{array}$ & 106 & 46,3 & $\begin{array}{l}\text { Patient's } \\
\text { relative }\end{array}$ & 81 & 35,4 \\
\hline $\begin{array}{l}\text { Provoked by relative } \\
\text { of the patient }\end{array}$ & 79 & 34,5 & $\begin{array}{l}\text { Bodily_parts (e.g. } \\
\text { hand/fist/foot }\end{array}$ & 91 & 39,7 & $\begin{array}{l}\text { Patient self } \\
\text { target }\end{array}$ & 17 & 7,4 & $\begin{array}{l}\text { Victim felt } \\
\text { threatened }\end{array}$ & 108 & 47,2 & $\begin{array}{l}\text { Patient only given } \\
\text { per oral medication }\end{array}$ & 3 & 1,3 & $\begin{array}{l}\text { Other patient's } \\
\text { relative }\end{array}$ & 31 & 13,5 \\
\hline $\begin{array}{l}\text { Provoked by other } \\
\text { relative }\end{array}$ & 5 & 2,2 & Spitting & 21 & 9,2 & $\begin{array}{l}\text { Other patient } \\
\text { targeted }\end{array}$ & 12 & 5,2 & $\begin{array}{l}\text { Victim } \\
\text { experienced } \\
\text { physical pain }\end{array}$ & 20 & 8,7 & $\begin{array}{l}\text { Patient given } \\
\text { intramuscular } \\
\text { injection } \\
\end{array}$ & 20 & 8,7 & Other relative, & 103 & 45,0 \\
\hline $\begin{array}{l}\text { Provoked by security } \\
\text { staff }\end{array}$ & 39 & 17,0 & $\begin{array}{l}\text { Dangerous } \\
\text { objects (e.g. } \\
\text { knife, } \\
\text { strangulation) } \\
\end{array}$ & 0 & 0,0 & $\begin{array}{l}\text { Relative of the } \\
\text { patient } \\
\text { targeted }\end{array}$ & 129 & 56,3 & $\begin{array}{l}\text { Visible injury or } \\
\text { need for any } \\
\text { treatment of } \\
\text { injury }\end{array}$ & 3 & 1,3 & $\begin{array}{l}\text { Patient given } \\
\text { intravenous injection }\end{array}$ & 46 & 20,1 & Security staff & 67 & 29,3 \\
\hline $\begin{array}{l}\text { Provoked by ward } \\
\text { assistant }\end{array}$ & 0 & 0,0 & & & & $\begin{array}{l}\text { Other relative } \\
\text { targeted }\end{array}$ & 3 & 1,3 & $\begin{array}{l}\text { Need for } \\
\text { treatment of } \\
\text { the victim by } \\
\text { physician }\end{array}$ & 0 & 0,0 & $\begin{array}{l}\text { Patient given } \\
\text { intramuscular and/or } \\
\text { intravenous injection }\end{array}$ & 66 & 28,8 & $\begin{array}{l}\text { Doctor, nurse } \\
\text { and/ or ward } \\
\text { assistant }\end{array}$ & 132 & 57,6 \\
\hline $\begin{array}{l}\text { Provoked by doctor/ } \\
\text { nurse }\end{array}$ & 7 & 3,1 & & & & $\begin{array}{l}\text { Security staff } \\
\text { targeted }\end{array}$ & 67 & 29,3 & & & & $\begin{array}{l}\text { Patient held } \\
\text { manually with force }\end{array}$ & 27 & 11,8 & & & \\
\hline $\begin{array}{l}\text { Provoked by help } \\
\text { with ADL }\end{array}$ & 1 & 0,4 & & & & $\begin{array}{l}\text { Ward assistant } \\
\text { targeted }\end{array}$ & 5 & 2,2 & & & & $\begin{array}{l}\text { Patient secluded or } \\
\text { isolated }\end{array}$ & 0 & 0,0 & & & \\
\hline $\begin{array}{l}\text { Provoked by being } \\
\text { denied something }\end{array}$ & 68 & 29,7 & & & & $\begin{array}{l}\text { Doctor/ nurse } \\
\text { targeted }\end{array}$ & 35 & 15,3 & & & & $\begin{array}{l}\text { Mechanical } \\
\text { restraints used }\end{array}$ & 2 & 0,9 & & & \\
\hline $\begin{array}{l}\text { Provoked by } \\
\text { required to take } \\
\text { medication }\end{array}$ & 14 & 6,1 & & & & & & & & & & & & & & & \\
\hline $\begin{array}{l}\text { Provoked by } \\
\text { something other }\end{array}$ & 3 & 1,3 & & & & & & & & & & & & & & & \\
\hline
\end{tabular}




\section{Table 3}

\section{Unadjusted logistic regressions of independent variables, variables significant in any of the regressions}

\begin{tabular}{|c|c|}
\hline Dependent variable & $\begin{array}{l}\text { "Hands-on" coercive } \\
\text { measures* }\end{array}$ \\
\hline \multirow[t]{2}{*}{ Independent variables } & $\begin{array}{lc}\text { Odds } & 95 \% \\
\text { ratio } & \mathrm{Cl}\end{array}$ \\
\hline & Low High \\
\hline
\end{tabular}

\section{Intravenous coercion}

P Odds

Ratio

$95 \%$
$\mathrm{Cl}$
Low High

Patient's relative involved in Doctor/nurse involved in measures to stop aggression measures to stop aggression

\section{P}

Provoked by required to take

NS

NS

NS

4.75

1.04

$21.7 \quad .045$

medication

Scores of means used by

0-4

Security staff targeted

Ward assistant targeted

Doctor/nurse targeted

$\begin{array}{llll}1.81 & 1.01 & 3.27 & .048\end{array}$

$\begin{array}{lllll}2.78 & 1.34 & 5.79 & \text { NS } & 6.31 \\ 006 & 3.94\end{array}$

$\begin{array}{lll} & & \text { NS } \\ 1.02 & 39.0 & .047\end{array}$

Score of consequence of

$\begin{array}{lll}1.02 & 39.0 & .047\end{array}$

aggression, range 0-9

$\begin{array}{lllllll}1.10 & 1.32 & .000 & 1.19 & 1.07 & 1.32 & .001\end{array}$

3.35

1.60

NS

NS

NS

*"hand-on" means that the patient was restrained by physical interventions i.e. physical restraint, mechanical restraint, intramuscular or intravenous injection 


\begin{tabular}{|c|c|c|c|c|c|c|c|c|c|c|c|c|c|c|c|c|}
\hline Dependent variable & \multicolumn{4}{|c|}{$\begin{array}{l}\text { "Hands-on" coercive } \\
\text { measures* }\end{array}$} & \multicolumn{4}{|c|}{ Intravenous coercion } & \multicolumn{4}{|c|}{$\begin{array}{l}\text { Patient's relative involved } \\
\text { in measures to stop } \\
\text { aggression }\end{array}$} & \multicolumn{4}{|c|}{$\begin{array}{l}\text { Doctor/nurse involved in } \\
\text { measures to stop aggression }\end{array}$} \\
\hline $\begin{array}{l}\text { Significant independent } \\
\text { variables }\end{array}$ & $\begin{array}{l}\text { Odds } \\
\text { Ratio }\end{array}$ & $\begin{array}{r}95 \\
c\end{array}$ & $\%$ & $P$ & $\begin{array}{l}\text { Odds } \\
\text { Ratio }\end{array}$ & & $\begin{array}{l}5 \% \\
\mathrm{Cl}\end{array}$ & $P$ & $\begin{array}{l}\text { Odds } \\
\text { Ratio }\end{array}$ & 95 & $\%$ & $P$ & $\begin{array}{l}\text { Odds } \\
\text { Ratio }\end{array}$ & & c\% & $P$ \\
\hline Doctor/nurse targeted & 3.10 & 1.43 & 6.72 & .004 & 4.41 & 1.96 & 9.91 & .000 & 3.35 & 1.60 & 7.03 & $\begin{array}{l}. \\
00 \\
1\end{array}$ & 10.4 & 3.07 & 35.5 & .000 \\
\hline $\begin{array}{l}\text { Score of consequence of } \\
\text { aggression, range } 0-9\end{array}$ & 1.21 & 1.11 & 1.33 & .000 & 1.20 & 1.09 & 1.34 & .001 & & & & & 1.09 & 1.01 & 1.18 & .034 \\
\hline
\end{tabular}




\section{APPENDIX 1}

\section{Report form SOAS-R/Indian}

Instructions:

This form is to be completed whenever observing any aggressive behaviour from any individual at the ward whereby aggression is defined as any verbal, non-verbal, or physical behaviour that was threatening to self, others or property, or physical behaviour that actually did harm to self, others, or property. The form should be used regardless of your opinion on the incident

Please note:

- category of aggressor (with hospital number for patient),

- gender of aggressor,

- date

- time,

- mark all applicable boxes with at least one mark in each column.

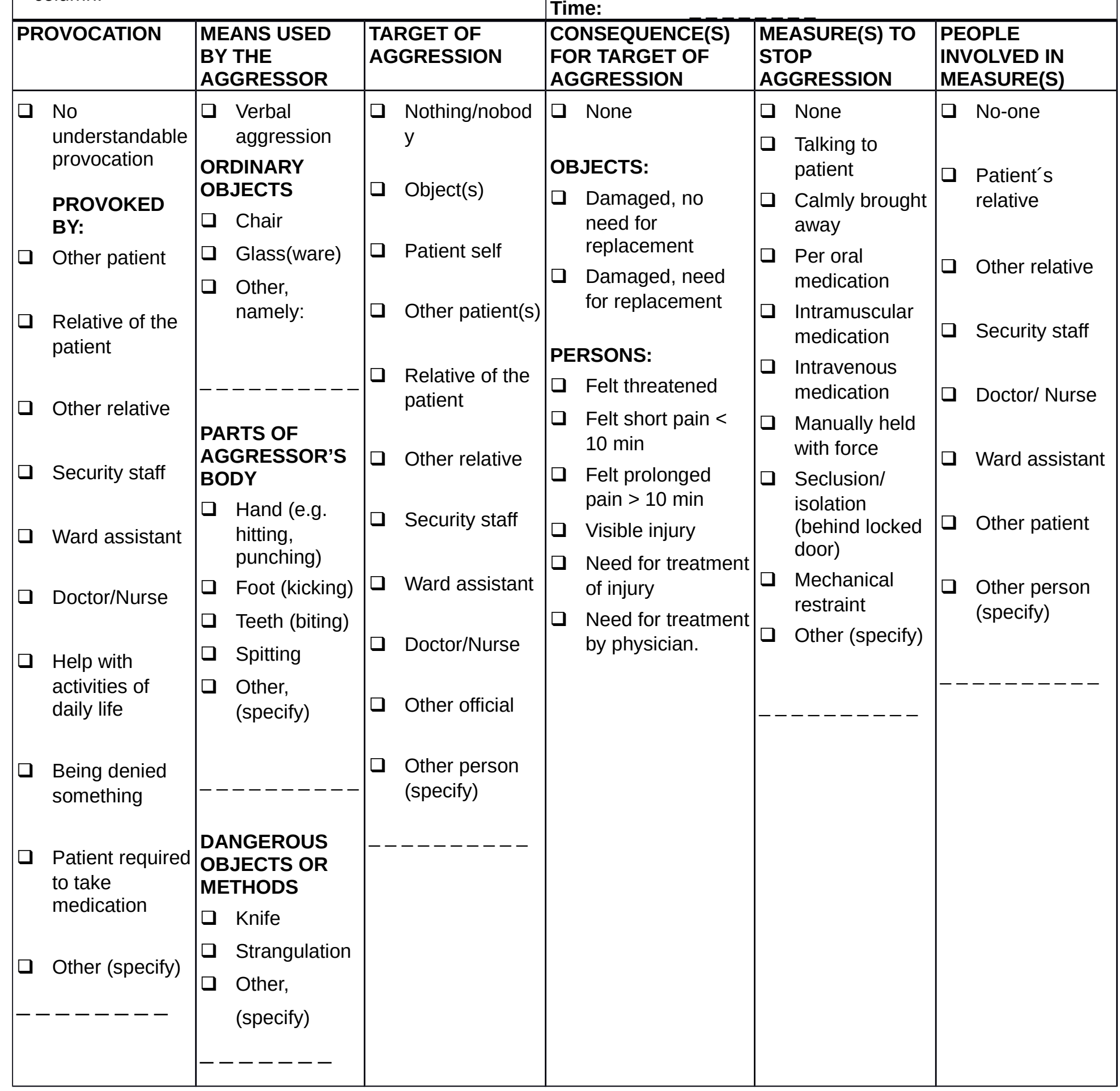

\section{Category of aggressor:}

( Patient:

a Relative, if relative, relative to what patient?

a Security staff

口 Ward assistant

D Doctor/Nurse

\section{Gender of aggressor:}

口 Male

口 Female

Ward:

Male

Female

Date:

Date.

CONSEQUENCE(S)

CONSEQUENCE

STOP 

Title:

Observational study of aggressive behaviour and coercion on an Indian acute ward

\section{Acknowledgements:}

The authors acknowledge the inputs by Dr Manoj Mutalik, Dr Manjushree, Dr Melvin D'Souza, Dr Mohan Kumar Notagar, Dr Merin Babu, Dr Nagaraj Moger, Dr Mohammed Shihab as non-interacting observers in the ward

\section{Conflict of Interest}

Authors do not have any conflict of interest to disclose. 


\section{Reviewer 1:}

1. The Authors claim in the last section, that "This is the first ever study reporting of non-professional care giver involvement in hospital care" may not be true.

Comment: During the process of writing up the paper as well as literature review, we observed that the studies looking in to the aggression in the wards are so sparse and we never came across any study which looked into this aspect. However, we understand that involvement of non-professional carers/family members is the norm in Indian setting. We would like to withdraw that statement and have made the changes in the text. If the reviewers know of any study, we will be happy to involve and reference them....

2. Have authors attempted to find out whether the aggression in wards without care givers in Indian setting is higher or lower?

Comment: The current study did not look in to this aspect of comparison of aggression in wards without caregivers for few reasons.

a. This study was designed as an observational study without impairing the daily activities in the ward and the hospital where the study was conducted, as a policy, does not have option of admitting patients without patient relatives/ attenders.

b. There are no studies which are similar in nature from Indian setting to compare the results as well.

However, we would like to acknowledge that there are studies studying aggression in wards without patient attenders from European countries, which have used the same instrument for recording aggression (SOAS-R). Comparison reveals that the aggression rates in Indian wards are significantly high. We believe this may be due to methodological reasons which we have already outlined in the manuscript. European studies are self reports by the staff on SOAS where as the current study used independent observer reports and the criteria for admissions which differ between the centers.

We are very grateful to the reviewer for his comments because we do indeed hope that our study can serve as a baseline for future comparative studies.

\section{Reviewer 2:}

1. Abstract should provide further information, e.g. scales used, who observed/rated etc. Conclusion should reflect the original research questions and findings

Comment: We thank the reviewer for his very usefl comment. We have now included the suggested information in the method section of the abstract. We completely revised the conclusion section to reflect reseach question and findings.

2. It may be better to report how many patients were admitted against their will; and the reported aggression in these patients compared with others.

Comment: Unfortunately, we do not have the data separating voluntary and involuntary admissions.

3. As many professionals rated different episodes, was there an inter-rater reliability established. 
Comment: SOAS-RI is an adaptation of the existing SOAS-R to Indian settings, incorporating the presence of extra people in Indian wards compared to standard European psychiatric wards. The SOAS-R has been extensively studied and was found to be a valid and reliable tool to study aggression.

A closer look into the instrument shows that the observer logs the factual information based on an actual act of violence or aggression. There is little room for interpretation of the incident. For example, an act of violence in which a patient hits the other with a fist, will invariably be documented by every observer in the same manner. For this reason, we did not need to carry out an inter-rater reliability test. However, all participating observers were specifically trained in using of the SOAS-RI in order to minimize any misunderstandings regarding the use of the report forms.

\section{How convincingly it was decided that the aggression was provoked?}

Comment: We have now added the following sentence to the methodology section of the manuscript.

"The observer subjectively judges whether the incident was provoked and by whom."

\section{Was there any correlation between diagnosis and aggression?}

Comment: We thank the reviewer for this very important point. We have now given full statistical details of our Kruskal Wallis test and presented the entire findings in the results section of the manuscript.

\section{The degrees of severity of aggression should be described for providing an idea to the readers besides the scores.}

Comment: We have now defined and given examples of what constitutes a severe incident on SOAS-RI

"Examples of incidents classed as severe (score>8) include: any physical attack resulting in a visible injury, physical pain or the victim feeling threatened, physical attack with a dangerous object resulting in the patient being restrained."

\section{More number of key words would be better.}

Comment: More key words added as per the suggestion given.

\section{What intravenous medications were given?}

Comment: The following text has been added.

"As a standard operating procedure in the ward, whenever a patient needs parenteral medications, intravenous haloperidol $5 \mathrm{mg}$ with lorazepam $4 \mathrm{mg}$ are given. Haloperidol $5 \mathrm{mg}$ with promethazine $25 \mathrm{mg}$ are given when intramuscularly injections are required."

\section{Please describe mechanical and manual restraint.}

Comment: For the purpose of this study, the type of restraints were defined according to the column "measures to stop aggression" in the SOAS-RI form. This is already been added as an appendix in the manuscript.

\section{Was the duration of restraint studied?}

Comment: Unfortunately we do not have the data about the duration of restraint. 
